\title{
Comparison of the Short-Term Effectiveness of Short-Wave Diathermy Treatment in Patients With Carpal Tunnel Syndrome: A Randomized Controlled Trial
}

\author{
Ahmet BOYACI, ${ }^{1}$ Ahmet TUTOĞLU, ${ }^{1}$ İrfan KOCA, ${ }^{2}$ Özcan KOCATÜRK, ${ }^{3}$ Esra ÇELEN ${ }^{1}$ \\ ${ }^{1}$ Department of Physical Medicine and Rehabilitation, Medical Faculty of Harran University, Şanlurfa, Turkey \\ ${ }^{2}$ Department of Physical Medicine and Rehabilitation, Medical Faculty of Gaziantep University, Gaziantep, Turkey \\ ${ }^{3}$ Department of Neurology, Medical Faculty of Harran University, Şanlıurfa, Turkey
}

\begin{abstract}
Objectives: This study aims to compare the effects of pulsed and continuous short wave diathermy (SWD) treatment in carpal tunnel syndrome. Patients and methods: This double-blind, randomized controlled trial included 30 patients ( 55 wrists) diagnosed with mild or moderate carpal tunnel syndrome. Patients were randomized into three groups and administered splinting and one of the following treatments: group 1: continuous SWD, group 2: pulsed SWD, and group 3: placebo SWD. The treatment was applied five days a week for 15 sessions. Patients were evaluated by the Tinel's test, Phalen's and reverse Phalen's maneuvers, carpal compression test, the Boston Carpal Tunnel Questionnaire (BCTQ: includes 2 parts, namely the symptom severity scale and functional status scale), and a visual analog scale. Median motor distal latency, median sensory distal latency, and nerve conduction velocity were measured. Electrophysiological findings, clinical tests, and scales were evaluated at the beginning and end of the therapy.

Results: A significant difference was observed in Phalen's maneuver positivity in the pulsed SWD group ( $<<0.05)$. Visual analog scale, BCTQfunctional status scale, BCTQ-symptom severity scale, median nerve motor and sensory latencies, and sensory nerve conduction velocity values were improved in both continuous and pulsed SWD groups $(p<0.05)$. The placebo group also showed improved BCTQ-functional status scale and median nerve motor distal latency $(p<0.05)$. BCTQ-symptom severity scale improved more in the continuous SWD group than the other groups $(p<0.01)$, and improved median nerve sensory distal latency and nerve conduction velocity parameters were observed in both SWD groups than the control group $(p<0.01)$.

Conclusion: Continuous and pulsed SWD therapies supported with splinting were effective for improving pain, hand function, and electrophysiological findings. In addition, continuous SWD seemed to be more effective in reducing symptom severity than pulsed and placebo SWD.

Keywords: Carpal tunnel syndrome; electrophysiological findings; hand function; short wave diathermy.
\end{abstract}

Carpal tunnel syndrome (CTS) is one of the most common entrapment neuropathies caused by compression of the median nerve within the carpal tunnel in the wrist. $^{1}$ The diagnosis is based on medical history, clinical and physical examination findings, as well as electrophysiological confirmation. Available conservative treatments include wrist-resting splints, local steroid injections, non-steroidal antiinflammatory drugs (NSAIDs), physical therapy, diuretics, vitamin B6, and activity modification. However, the efficacy of these treatments remains controversial. ${ }^{2,3}$
Short-wave diathermy (SWD) is a form of electromagnetic therapy used at a frequency of $27.12 \mathrm{MHz}$ in continuous or pulsed forms. Molecular distortion occurs due to the movement of ions in the electromagnetic field, and heat is generated in the deep tissues with induced eddy currents. ${ }^{4}$ In addition to the effects of SWD on the tissues, healing is stimulated with increased vascular circulation and pain threshold, and decreased pain and chronic inflammation. ${ }^{5}$ It is thought that these effects cannot be explained solely by the heating effect, and some of the therapeutic effects of SWD treatment

Received: October 29, 2013 Accepted: April 26, 2014 Published online: October 12, 2014

Correspondence: Ahmet Boyacı, M.D. Harran Üniversitesi Tıp Fakültesi Fiziksel Tıp ve Rehabilitasyon Anabilim Dalı, 63300 Şanlıurfa, Turkey.

Tel: +90 414 - 3183000 e-mail: drboyaci@hotmail.com

๑2014 Turkish League Against Rheumatism. All rights reserved. 
are dependent on the mutual interaction of electrical/magnetic fields and their interactions with biological tissues. ${ }^{6,7}$ Although pulsed SWD (minimal or no heating effect) has shown favorable effects such as increased tissue healing, hematoma resorption, nerve regeneration and collagen deposition, and reduced inflammation and swelling, ${ }^{4,8-10}$ its efficacy remains controversial due to the limited number of relevant studies.,11

The aim of the current study was to evaluate the differences between pulsed SWD, continuous SWD, and placebo treatment in terms of their effects on pain, clinical findings, hand function, and electrophysiological findings in patients with CTS.

\section{PATIENTS AND METHODS}

A double-blind, randomized controlled trial was designed. Patients diagnosed with mild or moderate idiopathic CTS by electrophysiological examination based on reference values used in our laboratory [median motor distal latency (mMDL) $>4.2 \mathrm{~m} / \mathrm{sec}$ or reduced sensory nerve conduction velocity (NCV) of the palm-wrist segment $<46 \mathrm{~m} / \mathrm{sec}$ ] were included. Patients with comorbid diseases which may affect peripheral nerves, splint use, a history of CTS surgery, forearm fracture, steroid injection into the carpal tunnel within the previous three months, polyneuropathy on electrophysiological examination, and severe CTS [mMDL of $>6 \mathrm{~m} / \mathrm{sec}$, the absence of a median nerve compound muscle action potential (CMAP), or the presence of thenar atrophy] were excluded. The institutional ethics committee approved the study protocol, and all subjects provided written informed consent. Patients were randomized into three groups using a closed-envelope method. Both hands of the patients with bilateral CTS were included in the same group, although the hands were evaluated separately.

A detailed neurological examination and tests for CTS including the Tinel's test, Phalen's and reverse Phalen's maneuvers, and carpal compression tests were performed. Visual analog scale (VAS) was used to assess the severity of hand and finger pain on a $10 \mathrm{~cm}$ scale. A Turkish version of the Boston Carpal Tunnel Questionnaire (BCTQ) was used to identify symptom severity and functional status of CTS patients. ${ }^{12,13}$ The questionnaire consists of two parts: symptom severity scale (BCTQ-SSS) and functional status scale (BCTQ-FSS).

Nerve conduction studies were performed by using an electromyography device (Model $9200 \mathrm{~K}$, Nihon Kohden, Tokyo, Japan) with superficial recording and stimulation electrodes. Median sensory nerve conductions were recorded from the second finger using the anti-dromic method. Compound muscle action potential was obtained from the abductor pollicis brevis muscle by supramaximal stimulation of the median nerve at the wrist level. Distal latencies and NCV were also recorded. Clinical and electrophysiological assessments were performed twice (before treatment and immediately after treatment) by blinded investigators.

Group 1 was applied continuous SWD and splints, group 2 was applied pulsed SWD, and group 3 was applied placebo SWD treatments. Treatment with a Curapulse 970 SWD device (Enraf-Nonius, Rotterdam, The Netherlands) was administered by the same physiotherapist for 15 sessions, 20 min per day, five days/week, for three weeks. During the administration, capacitor electrodes with a diameter of $10 \mathrm{~cm}$ were used. The electrodes were placed parallel to the wrist, facing the carpal tunnel region, while the elbow was flexed $90^{\circ}$ and the wrist was in the neutral position with a distance of $2 \mathrm{~cm}$ to the volar surface, and $3 \mathrm{~cm}$ to the dorsal surface. In continuous administration, an intensity of position 4 was used. In intermittent administrations; a pulse duration of $400 \mu \mathrm{s}$, a pulse frequency of $82 \mathrm{~Hz}$, and an intensity of position 6 were used. Starting from one week before the study and throughout the study, patients were asked to refrain from using NSAIDs or analgesic medications. All patients were stabilized with a neutral $\left(0-5^{\circ}\right.$ extended $)$ custom-molded thermoplastic volar wrist splint at night during the treatment period. ${ }^{14}$

\section{Statistical analysis}

Statistical analyses were carried out by using the SPSS for Windows version 15.0 software program (SPSS Inc., Chicago, IL, USA). Chisquared test was used to compare categorical data between the groups, and the McNemar's test was used to compare categorical data within the groups. Wilcoxon signed-rank test was used to identify significant differences between the 
pre- and post-treatment results within the groups. A Kruskal Wallis variance analysis was used, and post hoc comparisons were performed with Mann Whitney $U$ test. All demographic and quantitative data are expressed in mean \pm standard deviation (SD). A $p$ value of $<0.05$ was considered statistically significant.

Power calculations based on a pilot study with the first 10 wrists to detect a significant difference in the BCTQ-SSS revealed scores of $37 \pm 7$ in group $1,32 \pm 7$ in group 2 , and $30 \pm 5$ in group 3, respectively. Based on these differences and the assumption of a two-tailed alpha-value of 0.05 (sensitivity 95\%) and a beta-value of 0.20 (study power: 80\%), we showed that at least 16 wrists were required in each group (G*Power 3 power analysis software: University of Düsseldorf, Germany). ${ }^{15}$

\section{RESULTS}

Flow diagram of the study is given in Figure 1. The baseline characteristics including age, gender, body mass index, VAS, BCTQ-SSS, BCTQFSS, mMDL, median sensory nerve conduction velocity ( $\mathrm{mSNCV}$ ), median sensory distal latency (mSDL), and positivity of the provocation tests for CTS were similar between the groups (all $p>0.05$ ) (Table 1).
With treatment, the only difference was observed in Phalen's maneuver which produced positive results in the pulsed SWD treatment group $(50 \%$ vs. $25 \% ; \mathrm{p}<0.05)$. In the continuous SWD and pulsed SWD groups, differences were observed in VAS, BCTQ-SSS, BCTQ-FSS, mMDL, mSNCV, and $\mathrm{mSDL}(\mathrm{p}<0.05$; Table 1$)$. In the placebo group, differences were observed only in BCTQ-FSS and mMDL (both $\mathrm{p}<0.05$ ) (Table 1).

When the groups were compared according to the delta $(\Delta)$ values of pre- and posttreatment parameters, differences were observed in BCTQ-SSS, mSNCV, and $\mathrm{mSDL}$ values (all $\mathrm{p}<0.05)$. The BCTQ-SSS scores were higher in the continuous SWD group than the other groups at the end of the treatment $(p<0.01)$. Significantly improved mSNCV and mSDL parameters in both SWD groups were observed compared to the placebo group (both $\mathrm{p}<0.01$ ) (Table 1).

\section{DISCUSSION}

In this study, patients with mild to moderate CTS showed significant improvements in terms of pain, symptom severity, function and electrophysiological parameters in both continuous and pulsed SWD treatment groups, whereas the placebo group

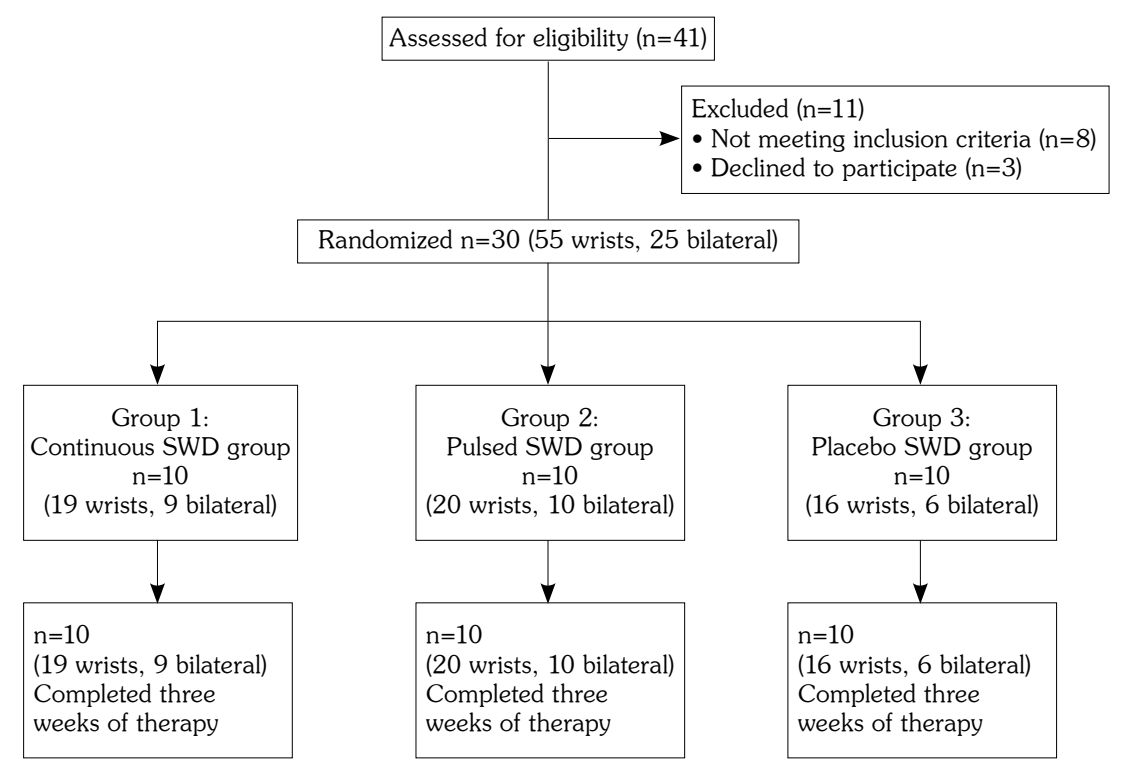

Figure 1. Flow diagram of the study. SWD: Short-wave diathermy. 
Table 1. Baseline characteristics of the study population, and comparison of pre- and post-treatment parameters and treatment effectiveness of the groups

\begin{tabular}{|c|c|c|c|c|c|c|c|c|c|c|}
\hline & \multicolumn{3}{|c|}{$\begin{array}{c}\text { Group } 1 \text { (Continuous SWD) } \\
\text { ( } \mathrm{n}=10,19 \text { wrist })\end{array}$} & \multicolumn{3}{|c|}{$\begin{array}{l}\text { Group } 2 \text { (Pulsed SWD) } \\
\qquad(\mathrm{n}=10,20 \text { wrist })\end{array}$} & \multicolumn{3}{|c|}{$\begin{array}{l}\text { Group } 3 \text { (Placebo SWD) } \\
\qquad(\mathrm{n}=10,16 \text { wrist })\end{array}$} & \multirow[b]{2}{*}{$p^{b}$} \\
\hline & $\mathrm{n}$ & Mean \pm SD & $p^{a}$ & $\mathrm{n}$ & Mean \pm SD & $p^{a}$ & $\mathrm{n}$ & Mean \pm SD & $p^{a}$ & \\
\hline Age (years) & & $44.10 \pm 9.93$ & & & $47.70 \pm 17.75$ & & & $50.10 \pm 11.39$ & & 0.299 \\
\hline \multicolumn{11}{|l|}{ Sex } \\
\hline Female & 8 & & & 9 & & & 9 & & & \\
\hline Male & 2 & & & 1 & & & 1 & & & \\
\hline Body mass index $\left(\mathrm{kg} / \mathrm{m}^{2}\right)$ & & $27.81 \pm 3.64$ & & & $28.87 \pm 4.86$ & & & $29.26 \pm 3.74$ & & 0.544 \\
\hline \multicolumn{11}{|l|}{ VAS } \\
\hline $\begin{array}{l}\text { Pre-treatment } \\
\text { Post-treatment }\end{array}$ & & $\begin{array}{l}7.63 \pm 2.13 \\
5.52 \pm 2.69\end{array}$ & $<0.001$ & & $\begin{array}{l}7.85 \pm 1.53 \\
5.65 \pm 2.20\end{array}$ & 0.001 & & $\begin{array}{l}7.56 \pm 1.50 \\
6.31 \pm 2.98\end{array}$ & 0.071 & $\begin{array}{l}0.681 \\
0.456\end{array}$ \\
\hline$\Delta$ VAS & & $-1.89 \pm 1.97$ & & & $-2.20 \pm 1.88$ & & & $-1.25 \pm 2.46$ & & 0.315 \\
\hline \multicolumn{11}{|l|}{ BCTQ-SSS } \\
\hline $\begin{array}{l}\text { Pre-treatment } \\
\text { Post-treatment }\end{array}$ & & $\begin{array}{l}37.10 \pm 9.59 \\
29.31 \pm 8.93\end{array}$ & $<0.001$ & & $\begin{array}{l}32.30 \pm 9.36 \\
28.65 \pm 8.38\end{array}$ & 0.003 & & $\begin{array}{l}32.12 \pm 7.22 \\
29.56 \pm 8.67\end{array}$ & 0.124 & $\begin{array}{l}0.134 \\
0.737\end{array}$ \\
\hline$\triangle \mathrm{BCTQ}-\mathrm{SSS}$ & & $-7.78 \pm 5.23 * \mathrm{q}$ & & & $-3.65 \pm 4.54$ & & & $-2.56 \pm 6.52$ & & 0.031 \\
\hline \multicolumn{11}{|l|}{ BCTQ-FSS } \\
\hline $\begin{array}{l}\text { Pre-treatment } \\
\text { Post-treatment }\end{array}$ & & $\begin{array}{r}23.84 \pm 6.15 \\
20.0 \pm 6.19\end{array}$ & 0.001 & & $\begin{array}{l}20.10 \pm 6.26 \\
17.90 \pm 5.98\end{array}$ & 0.006 & & $\begin{array}{l}18.87 \pm 6.50 \\
17.68 \pm 6.61\end{array}$ & 0.048 & $\begin{array}{l}0.056 \\
0.483\end{array}$ \\
\hline$\triangle \mathrm{BCTQ}-\mathrm{FSS}$ & & $-3.84 \pm 4.33$ & & & $-2.20 \pm 3.38$ & & & $-1.18 \pm 2.07$ & & 0.132 \\
\hline \multicolumn{11}{|l|}{$\begin{array}{l}\text { Median nerve motor } \\
\text { distal latency }(\mathrm{m} / \mathrm{sec})\end{array}$} \\
\hline $\begin{array}{l}\text { Pre-treatment } \\
\text { Post-treatment }\end{array}$ & & $\begin{array}{l}4.43 \pm 0.65 \\
4.14 \pm 0.50\end{array}$ & 0.001 & & $\begin{array}{l}4.69 \pm 0.79 \\
4.50 \pm 0.84\end{array}$ & 0.003 & & $\begin{array}{l}4.37 \pm 0.53 \\
4.27 \pm 0.52\end{array}$ & 0.017 & $\begin{array}{l}0.420 \\
0.370\end{array}$ \\
\hline $\begin{array}{l}\Delta \text { Median nerve motor } \\
\text { distal latency }(\mathrm{m} / \mathrm{sec})\end{array}$ & & $-0.29 \pm 0.34$ & & & $-0.19 \pm 0.26$ & & & $-0.10 \pm 0.17$ & & 0.052 \\
\hline \multicolumn{11}{|l|}{$\begin{array}{l}\text { Median nerve sensory } \\
\text { velocity }(\mathrm{m} / \mathrm{sec})\end{array}$} \\
\hline $\begin{array}{l}\text { Pre-treatment } \\
\text { Post-treatment }\end{array}$ & & $\begin{array}{l}39.45 \pm 5.22 \\
42.90 \pm 4.67\end{array}$ & 0.003 & & $\begin{array}{l}36.86 \pm 6.35 \\
39.30 \pm 5.22\end{array}$ & $<0.001$ & & $\begin{array}{l}39.01 \pm 4.89 \\
39.65 \pm 5.11\end{array}$ & 0.239 & $\begin{array}{l}0.386 \\
0.089\end{array}$ \\
\hline $\begin{array}{l}\Delta \text { Median nerve sensory } \\
\text { velocity }(\mathrm{m} / \mathrm{sec})\end{array}$ & & $3.44 \pm 4.399$ & & & $2.44 \pm 2.58 \dagger$ & & & $0.63 \pm 2.24$ & & 0.011 \\
\hline \multicolumn{11}{|l|}{$\begin{array}{l}\text { Median nerve sensory } \\
\text { distal latency }(\mathrm{m} / \mathrm{sec})\end{array}$} \\
\hline $\begin{array}{l}\text { Pre-treatment } \\
\text { Post-treatment }\end{array}$ & & $\begin{array}{l}2.28 \pm 0.34 \\
2.15 \pm 0.29\end{array}$ & 0.007 & & $\begin{array}{l}2.60 \pm 0.64 \\
2.47 \pm 0.61\end{array}$ & 0.004 & & $\begin{array}{l}2.28 \pm 0.31 \\
2.25 \pm 0.33\end{array}$ & 0.083 & $\begin{array}{l}0.452 \\
0.257\end{array}$ \\
\hline $\begin{array}{l}\Delta \text { Median nerve sensory } \\
\text { distal latency }(\mathrm{m} / \mathrm{sec})\end{array}$ & & $-0.12 \pm 0.199$ & & & $-0.13 \pm 0.14 \dagger$ & & & $-0.02 \pm 0.06$ & & 0.008 \\
\hline
\end{tabular}

showed improvements only in function and some electrophysiological parameters. Significant improvements were observed in electrophysiological parameters in both SWD groups compared to the placebo group, and in symptom severity in the continuous SWD group compared to the other groups.

The absence of significant differences between the groups in terms of pain, function, or mMDL after treatment was attributed primarily to the use of the splint treatment in the placebo group. ${ }^{2}$ Moreover, placebo analgesia induced in the placebo group might have contributed to this result. ${ }^{16}$ In a previous study investigating the effectiveness of continuous and pulsed SWD treatments in mild or moderate CTS, it was shown that these treatments were effective on subjective clinical parameters, however, the efficacy was not superior to that 
of the placebo. Moreover, improved mSNCV following treatment in the continuous SWD group was demonstrated. ${ }^{17}$ In the current study, improved mSNCV in both SWD treatment groups was shown. This significantly increased sensory NCV in the continuous SWD groups in both studies may be explained by the thermal effects of continuous SWD on the peripheral nerves. The longer duration of treatment and the application of a splint in the present study, as opposed to the nerve gliding exercises in the previous study, may also explain the electrophysiological improvement in the pulsed SWD treatment group. To the best of our knowledge, no study has been published on the effectiveness of SWD on NCV other than this study. ${ }^{17}$ However, some studies have demonstrated the efficacy of ultrasound therapy on NCV in mild-to-moderate CTS. ${ }^{18,19}$ Additionally, corticosteroid phonophoresis, steroids, and procaine hydrochloride injection treatments in patients with CTS have improved electrophysiological parameters. ${ }^{20,21}$ Improved electrophysiological parameters with pulsed SWD treatment reported herein suggest that this treatment might also have thermal effects. Pulsed SWD can increase tissue temperature, depending on the dose administered. ${ }^{22,23}$ Further studies are needed to establish the appropriate dose and duration.

Limitations of the current study include its small sample size, lack of long-term follow-up, and the fact that evaluations were performed only at the end of the treatment. Also, the use of splint treatment in all groups made it difficult to explain the effects of treatment with only continuous or pulsed SWD.

In conclusion, continuous and pulsed SWD treatment together with splinting demonstrated positive effects on pain, clinical findings, hand function, and electrophysiological findings in mild to moderate CTS. Additionally, continuous SWD treatment appears to be more effective in reducing symptom severity than pulsed or placebo SWD treatment.

\section{Declaration of conflicting interests}

The authors declared no conflicts of interest with respect to the authorship and/or publication of this article.

\section{Funding}

The authors received no financial support for the research and/or authorship of this article.

\section{REFERENCES}

1. de Krom MC, Knipschild PG, Kester AD, Thijs CT, Boekkooi PF, Spaans F. Carpal tunnel syndrome: prevalence in the general population. $\mathrm{J}$ Clin Epidemiol 1992;45:373-6.

2. Piazzini DB, Aprile I, Ferrara PE, Bertolini C, Tonali $\mathrm{P}$, Maggi $\mathrm{L}$, et al. A systematic review of conservative treatment of carpal tunnel syndrome. Clin Rehabil 2007;21:299-314.

3. O'Connor D, Marshall S, Massy-Westropp N. Nonsurgical treatment (other than steroid injection) for carpal tunnel syndrome. Cochrane Database Syst Rev 2003:CD003219.

4. Goats GC. Pulsed electromagnetic (short-wave) energy therapy. Br J Sports Med 1989;23:213-6.

5. Shields N, Gormley J, O'Hare N. Short-wave diathermy: current clinical and safety practices. Physiother Res Int 2002;7:191-202.

6. Tsong TY. Deciphering the language of cells. Trends Biochem Sci 1989;14:89-92.

7. Low J. Dosage of some pulsed shortwave clinical trials. Physiotherapy 1995;81:611-6.

8. Wilson DH, Jagadeesh P, Newman PP, Harriman DG. The effects of pulsed electromagnetic energy on peripheral nerve regeneration. Ann N Y Acad Sci 1974;238:575-85.

9. Santiesteban AJ, Grant C. Post-surgical effect of pulsed shortwave therapy. J Am Podiatr Med Assoc 1985;75:306-9.

10. Pasila M, Visuri T, Sundholm A. Pulsating shortwave diathermy: value in treatment of recent ankle and foot sprains. Arch Phys Med Rehabil 1978;59:383-6.

11. Kitchen S, Partridge C. Review of shortwave diathermy continuous and pulsed patterns. Physiotherapy 1992;78:243-52.

12. Levine DW, Simmons BP, Koris MJ, Daltroy LH, Hohl GG, Fossel AH, et al. A self-administered questionnaire for the assessment of severity of symptoms and functional status in carpal tunnel syndrome. $\mathrm{J}$ Bone Joint Surg [Am] 1993;75:1585-92.

13. Sezgin M, Incel NA, Serhan S, Camdeviren $H$, As I, Erdoğan C. Assessment of symptom severity and functional status in patients with carpal tunnel syndrome: reliability and functionality of the Turkish version of the Boston Questionnaire. Disabil Rehabil 2006;28:1281-5.

14. Kruger VL, Kraft GH, Deitz JC, Ameis A, Polissar L. Carpal tunnel syndrome: objective measures and splint use. Arch Phys Med Rehabil 1991;72:517-20.

15. Faul F, Erdfelder E, Buchner A, Lang AG. Statistical power analyses using G*Power 3.1: tests for correlation 
and regression analyses. Behav Res Methods 2009;41:1149-60.

16. Zubieta JK, Stohler CS. Neurobiological mechanisms of placebo responses. Ann N Y Acad Sci 2009;1156:198-210.

17. Özçete Z.A, Öztürk C, Yağız On A, Hepgüler S, Atamaz Çalış F. Effect of short wave therapy in idiopathic carpal tunnel syndrome: A randomized double-blind controlled study. Turk J Phys Med Rehab 2013;59:103-7.

18. Duymaz T, Sindel D, Kesiktaş N, Müslümanoğlu L. Efficacy of some combined conservative methods in the treatment of carpal tunnel syndrome: A randomized controlled clinical and electrophysiological trial. Turk J Rheumatol 2012;27:38-46.

19. Ebenbichler GR, Resch KL, Nicolakis P, Wiesinger GF, Uhl F, Ghanem AH, et al. Ultrasound treatment for treating the carpal tunnel syndrome: randomised "sham" controlled trial. BMJ 1998;316:731-5.

20. Soyupek F, Kutluhan S, Uslusoy G, Ilgun E, Eris S, Askin A. The efficacy of phonophoresis on electrophysiological studies of the patients with carpal tunnel syndrome. Rheumatol Int 2012;32:3235-42.

21. Karadağ O, Omaç OK, Tok F, Ozgül A, Odabaşi Z. Effects of steroid with repetitive procaine $\mathrm{HCl}$ injection in the management of carpal tunnel syndrome: an ultrasonographic study. J Neurol Sci 2012;316:76-8.

22. Murray CC, Kitchen S. Effect of pulse repetition rate on the perception of thermal sensation with pulsed shortwave diathermy. Physiother Res Int 2000;5:73-84.

23. Silverman DR, Pendleton L. A comparison of the effects of continuous and pulsed short-wave diathermy on peripheral circulation. Arch Phys Med Rehabil 1968;49:429-36. 